\title{
Ultrasound in the diagnosis of malignant pancreatic tumours
}

\author{
G. ENGELHART AND U. W. BLAUENSTEIN \\ From the Department of Gastroenterology, Surgical and Medical Clinics, University Hospital, \\ Basel, Switzerland
}

SUMMARY Ultrasonic scanning of the upper abdomen is a valuable method in diagnosing malignant pancreatic tumours. A series of 12 patients is presented. The method also provides information about the size of the gallbladder and the condition of the liver parenchyma.

There is a lack of minor diagnostic procedures to visualize the pancreas. Two-dimensional ultrasonic scanning fulfils the conditions of such a screening method, and has proved to be valuable in diagnosing malignant lesions in the pancreas.

The results in a series of 12 patients with a malignant growth in the pancreas are presented.

\section{Method}

The apparatus used is a Picker ultrasonic laminograph (model MDU-661-BU) equipped with a Tektronix storage oscilloscope and a camera of Polaroid type to photograph the screen: transducer, $2 \mathrm{Mc}$, diameter $10 \mathrm{~mm}$.

The scanning is performed manually in direct contact with the skin of the patient. Transverse sectional planes are recorded at intervals of $1.5 \mathrm{~cm}$ between the xiphoid and the umbilicus. For special purposes these sections can be supplemented by one or more sections in the longitudinal or oblique plane.

\section{Patients and Results}

The data for 12 patients with a malignant growth in the pancreas are summarized in the Table.
CASES 1 TO 10

The first 10 patients with previously unknown malignant disease are of special interest. Painless jaundice, itching, and weight loss were the major presenting symptoms.

Clinically, the liver was enlarged in six and the gallbladder palpable in five of them. Only two patients complained of upper abdominal pain radiating to the back. In one of them, this pain could be related to tumorous infiltration of the coeliac nerves; the other had a technically operable tumour without metastases.

Biochemical data were compatible with obstructive jaundice. Drug jaundice could be excluded by careful interrogation; none had gallstones and/or inflammatory biliary disease associated with the pancreatic tumour.

Two-dimensional sonography of the upper abdomen showed a tumour in the region of the head of the pancreas in all 10 patients (Figs. 1, 2, 3 , and 5). The gallbladder was demonstrated to be enlarged in all the cases (Figs. 1, 3, 4, and 5). Sonographically, no liver metastases were found in seven cases, but there was strong suspicion of secondaries in the remaining three cases (Fig. 3). The sonographic findings were confirmed by laparotomy in nine and by necropsy in one case (Table ).

Six of the 10 patients had an operable tumour without metastases. Radical surgery with duodeno-pancreatectomy was performed in four patients; they are in good health two to seven 


\begin{tabular}{|c|c|c|c|c|c|c|c|c|}
\hline \multirow{2}{*}{$\begin{array}{l}\text { Case } \\
\text { No. }\end{array}$} & \multirow[t]{2}{*}{ Sex } & \multirow{2}{*}{$\begin{array}{l}\text { Age } \\
(y r)\end{array}$} & \multirow{2}{*}{ Symptoms and Clinical Signs } & \multirow{2}{*}{$\begin{array}{l}\text { Time between } \\
\text { Onset of Symptoms } \\
\text { and Diagnosis }\end{array}$} & \multicolumn{3}{|c|}{ Biochemical Data before Operation } & \multirow[t]{2}{*}{ Barium Meal } \\
\hline & & & & & $\begin{array}{l}\text { Bilirubin } \\
(m g \%)\end{array}$ & $\begin{array}{l}\text { SGPT } \\
(I U)\end{array}$ & $\begin{array}{l}\text { Alkaline } \\
\text { Phosphatase } \\
\text { (Bodansky } \\
\text { units) }\end{array}$ & \\
\hline 1 & $\mathbf{F}$ & 61 & $\begin{array}{l}\text { Painless jaundice, itching; liver } \\
\text { enlarged, gallbladder palpable, } \\
\text { weight loss } 3 \mathrm{~kg}\end{array}$ & 4 weeks & 21 & 62 & 71 & Normal \\
\hline 2 & $\mathbf{M}$ & 68 & $\begin{array}{l}\text { Painless jaundice, itching, liver } \\
\text { slightly enlarged, gallbladder palpable, } \\
\text { weight loss } 3 \mathrm{~kg}\end{array}$ & 5 weeks & 22 & 52 & 20 & Normal \\
\hline 3 & $\mathbf{M}$ & 50 & $\begin{array}{l}\text { Painless jaundice, itching, liver } \\
\text { enlarged, gallbladder not palpable, } \\
\text { weight loss } 4 \mathrm{~kg}\end{array}$ & 4 weeks & 10 & 45 & 13 & Normal \\
\hline 4 & $\mathbf{F}$ & 72 & $\begin{array}{l}\text { Nausea and vomiting, painless } \\
\text { jaundice, no itching, normal liver, } \\
\text { gallbladder palpable, weight loss } 7 \mathbf{~ k g}\end{array}$ & 5 weeks & 10 & 110 & 26 & Normal \\
\hline 5 & $\mathbf{M}$ & 65 & $\begin{array}{l}\text { Painless jaundice, itching, liver } \\
\text { slightly enlarged, gallbladder not } \\
\text { palpable, weight loss } 3 \mathrm{~kg}\end{array}$ & 4 weeks & 31 & 108 & 19 & Normal \\
\hline 6 & $\mathbf{M}$ & 73 & $\begin{array}{l}\text { Occasional vomiting, painless } \\
\text { jaundice, no itching, liver and } \\
\text { gallbladder normal, no weight loss }\end{array}$ & 8 weeks & 14 & 39 & 19 & $\begin{array}{l}\text { Stenosis in third } \\
\text { part of duodenum, } \\
\text { mucosal pattern } \\
\text { destroyed }\end{array}$ \\
\hline 7 & $\mathbf{F}$ & 75 & $\begin{array}{l}\text { Painless jaundice, no itching; liver } \\
\text { enlarged, gallbladder palpable, no } \\
\text { weight loss }\end{array}$ & 8 weeks & 17 & 24 & 15 & Normal \\
\hline 8 & $\mathbf{F}$ & 60 & $\begin{array}{l}\text { Occasional vomiting, colicky upper } \\
\text { abdominal pain radiating to the } \\
\text { back; liver and gallbladder normal } \\
\text { weight loss } 4 \mathrm{~kg}\end{array}$ & 10 weeks & 25 & 44 & 21 & $\begin{array}{l}\text { Normal } \\
\text { (duodenography } \\
\text { in hypotony: } \\
\text { normal) }\end{array}$ \\
\hline 9 & $\mathbf{F}$ & 56 & $\begin{array}{l}\text { Pain in the back, then jaundice and } \\
\text { itching; liver slightly enlarged with } \\
\text { nodular surface, gallbladder } \\
\text { palpable }\end{array}$ & 8 weeks & 16 & 35 & 8 & Normal \\
\hline 10 & $\mathbf{M}$ & 79 & $\begin{array}{l}\text { Painless jaundice, no itching; liver } \\
\text { slightly enlarged, gallbladder not } \\
\text { palpable, weight loss } 7 \text { kg }\end{array}$ & 11 weeks & 11 & 75 & 24 & Normal \\
\hline 11 & $\mathbf{F}$ & 58 & $\begin{array}{l}\text { Severe itching, no jaundice } 7 \mathrm{mth} \\
\text { after mastectomy for cancer; liver } \\
\text { normal size, gallbladder not palpable, } \\
\text { no weight loss }\end{array}$ & 6 weeks & 11 & 112 & 25 & $\begin{array}{l}\text { Not } \\
\text { performed }\end{array}$ \\
\hline 12 & $\mathbf{F}$ & 70 & $\begin{array}{l}\text { Six mth previously palliative surgery } \\
\text { for inoperable tumour in head of } \\
\text { pancreas; now again jaundice } \\
\text { and septicaemia }\end{array}$ & & 21 & 32 & 33 & $\begin{array}{l}\text { Not } \\
\text { performed }\end{array}$ \\
\hline
\end{tabular}

Table Summarized data for 12 patients with malignant pancreatic tumours

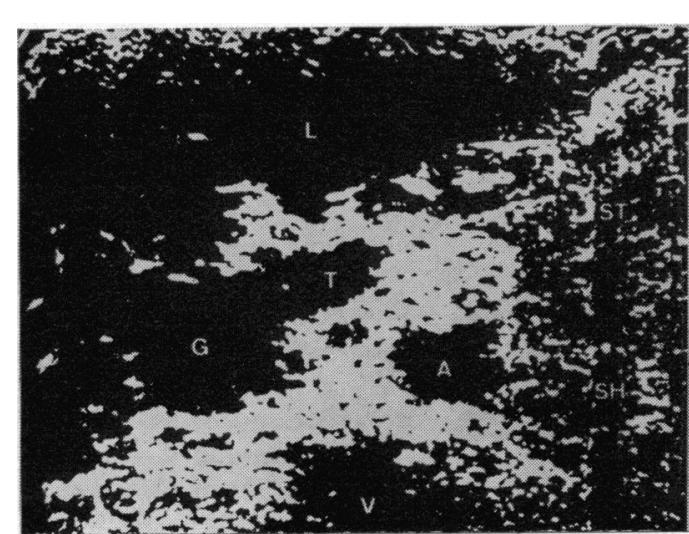

Fig. 1a Transverse ultrasonic scan of the upper abdomen of case 7 showing a tumour in the head of the pancreas, enlarged gallbladder, no liver metastases (surgically confirmed).

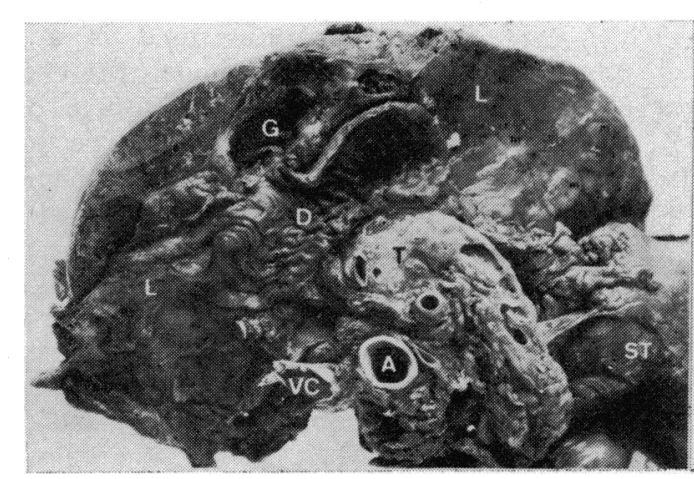

Fig. 1b Transverse necropsy section of case 7. The inferior vena cava is thrombosed and the liver metastases are partly marked.

(The key used here and in the other figures is on page 446.) 
Grossly enlarged gallbladder, no liver or peritoneal metastases

Grossly enlarged gallbladder, no metastases

Gallbladder enlarged, no metastases

Gallbladder enlarged, no metastases

Gallbladder enlarged, no metastases seen

Not performed

Grossly enlarged gallbladder, no metastases

Gallbladder enlarged, no metastases seen

Liver and peritoneal metastases, ascites, gallbladder enlarged

Gallbladder enlarged, no metastases

One metastatic growth in each lobe of liver, gallbladder enlarged
Tumour of head of pancreas, enlarged gallbladder $5 \mathrm{~cm}$, no liver metastases

Tumour of head of pancreas, enlarged gallbladder $4 \mathrm{~cm}$, no liver metastases

Tumour of head of pancreas, enlarged gallbladder $5 \mathrm{~cm}$, no liver metastases

Tumour of head of pancreas, enlarged gallbladder $4 \mathrm{~cm}$, no liver metastases

Tumour of head of pancreas, enlarged gallbladder $4 \mathrm{~cm}$, strong suspicion of small liver metastases

Tumour of head of pancreas, enlarged gallbladder, small liver metastases

Tumour of head of pancreas, gallbladder enlarged, no liver metastases

Tumour of head of pancreas, gallbladder enlarged, no liver metastases. Control $6 \mathrm{mth}$ later: pancreatic tumour much bigger, liver metastases

Tumour of head of pancreas, gallbladder enlarged, liver metastases

Tumour of head and body of pancreas, gallbladder enlarged, no metastases

Tumour in head of pancreas, enlarged gallbladder, suspicion of one metastatic nodule in right lobe of liver
Tumour confirmed; duodeno-pancreatectomy, no metastases, patient well two months after operation

Tumour confirmed; duodeno-pancreatectomy, no metastases, patient well $3 \mathrm{mth}$ later

Tumour confirmed; duodeno-pancreatectomy, no metastases, patient well $3 \mathrm{mth}$ after surgery

Tumour confirmed; duodeno-pancreatectomy, no metastases, patient well 3 mth after surgery

Tumour confirmed, inoperable situation with regional and liver metastases; cholecystojejunostomy, patient well 4 months later

Pancreatic tumour and liver metastases confirmed; cholecysto-jejunostomy, patient well $2 \mathrm{mth}$ later

First operation: pancreatic tumour confirmed, no metastases found, cholecysto-jejunostomy performed. Second operation: 4 weeks later inoperable situation with diffuse small liver metastases. Diagnosis confirmed at necropsy

First operation: cholecystostomy. Second operation, 10 days later: tumour confirmed, no metastases found; choledocho-jejunostomy performed

Diagnosis confirmed at necropsy

Big tumour of head and body of pancreas confirmed; inoperable situation with regional metastases; no liver metastases; cholecysto-jejunostomy performed

Operation showed metastatic growth in head of pancreas with obstruction of bile duct, liver metastases; cholecysto-jejunostomy performed

No necropsy performed

\section{Table-continued}

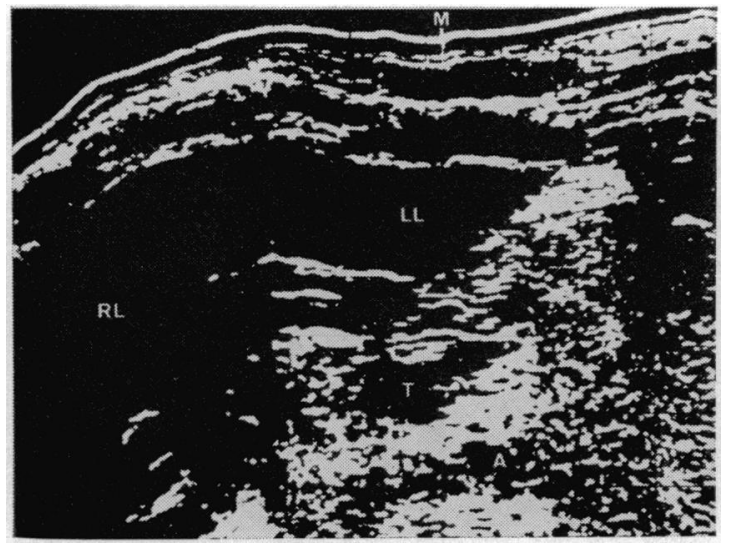

Fig. 2a Transverse ultrasonic sections of upper abdomen showing a tumour of the head of the pancreas (case 8) in the preoperative situation, but no liver metastases (surgically confirmed).

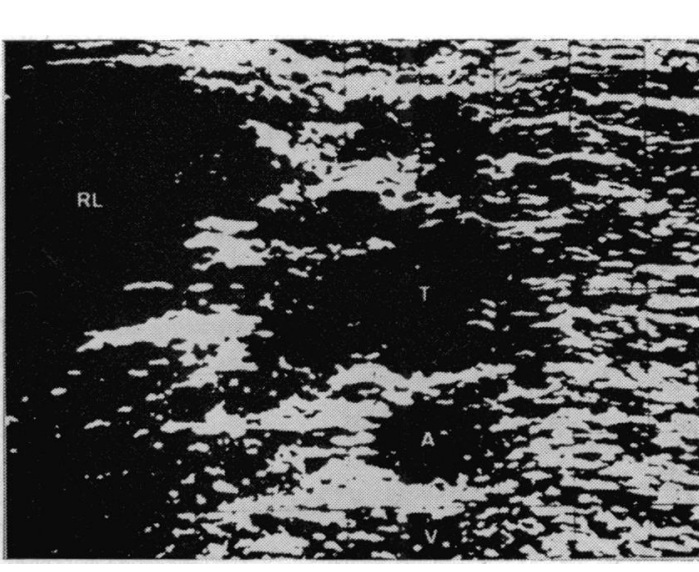

Fig. 2b Follow up six months after palliative surgery showing markedly increased pancreatic tumour (case 8). 


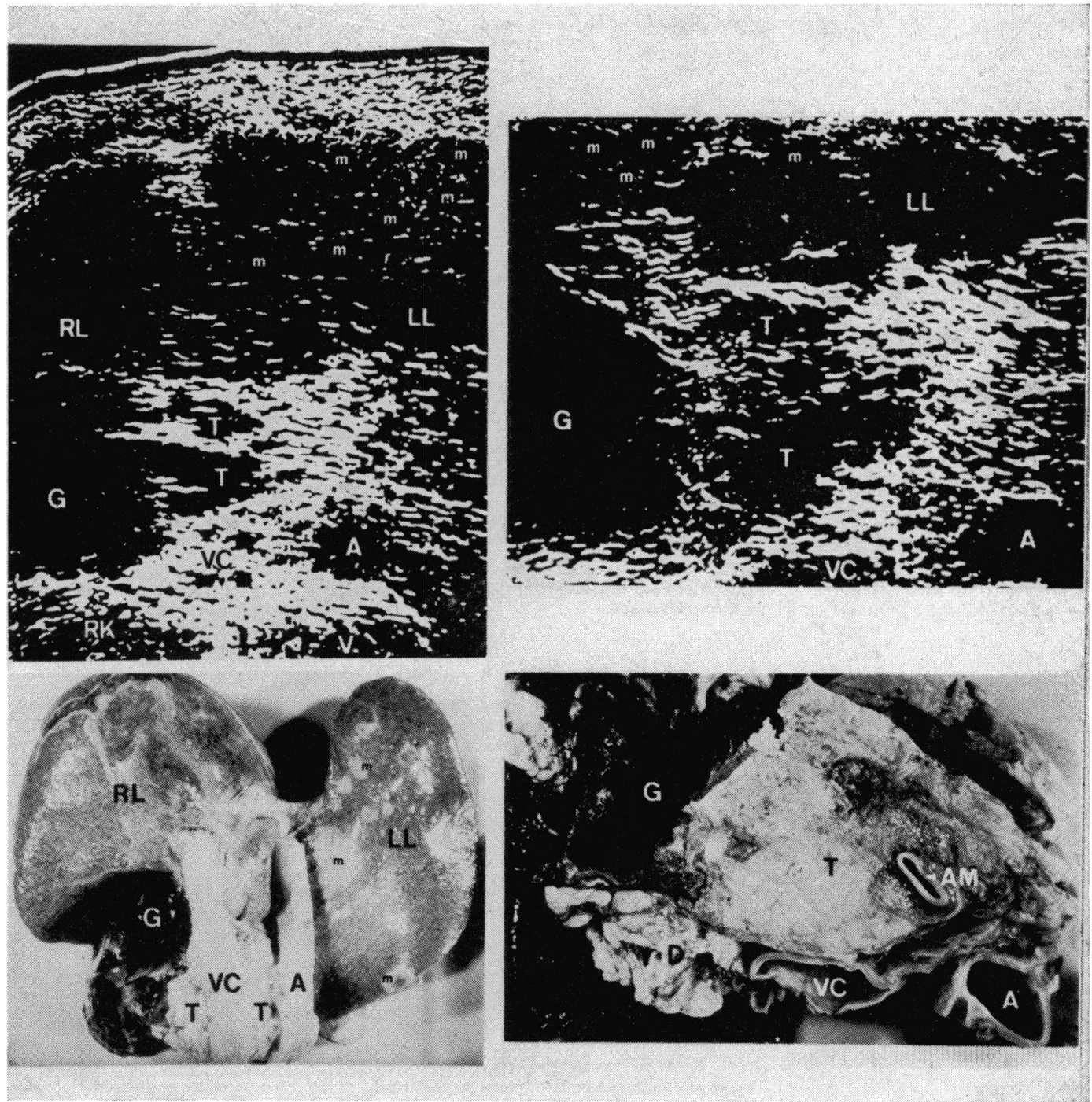

Fig. 3 Top left: tranverse ultrasonic scan of the upper abdomen in case 9 showing tumour of the head of the pancreas, enlarged gallbladder, liver metastases. Bottom left: dorsal view of liver, gallbladder, pancreatic tumour, and great abdominal vessels at necropsy. Top and bottom right: transverse ultrasonic scan and corresponding necropsy section through the pancreatic tumour. The metastases are partly marked.

$\mathbf{L}=$ liver, $\mathbf{G}=$ gallbladder, $\mathbf{D}=$ duodenum, $\mathbf{S T}=$ stomach, $\mathbf{T}=$ tumour, VC=vena cava inf., $A=$ aorta, $V=$ vertebral column, $R L$ and $L L=$ right and left lobes of liver, $R K=$ right kidney, $\mathbf{R I}=\mathrm{rib}, \mathbf{P R}=$ pancreatic region, $\mathbf{A M}=$ art. mesent. sup, $\mathbf{S H}=$ shadow caused by stomach, $M R=M m$ recti abdominis, $T_{H}$ or $\mathrm{T} B=$ tumour of head or body, $M=$ midline, $m=$ metastases 


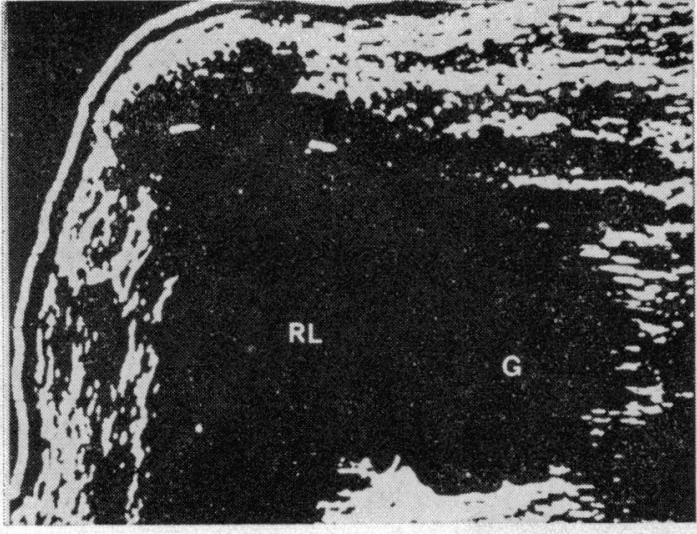

Fig. 4a

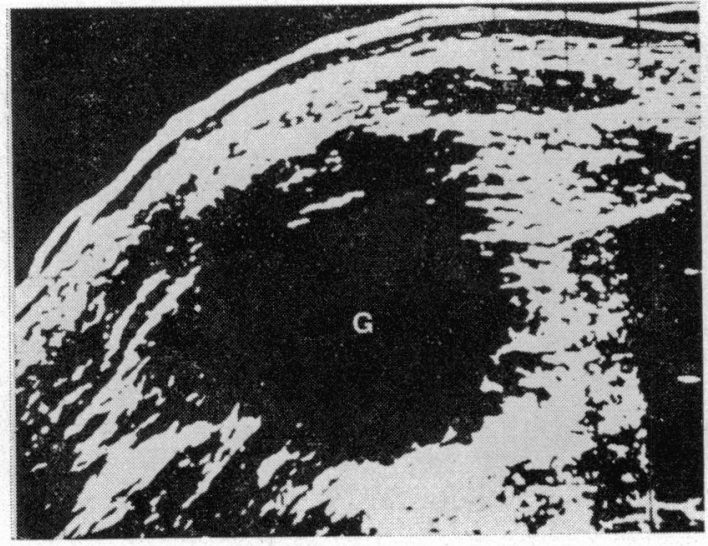

Fig. 4b

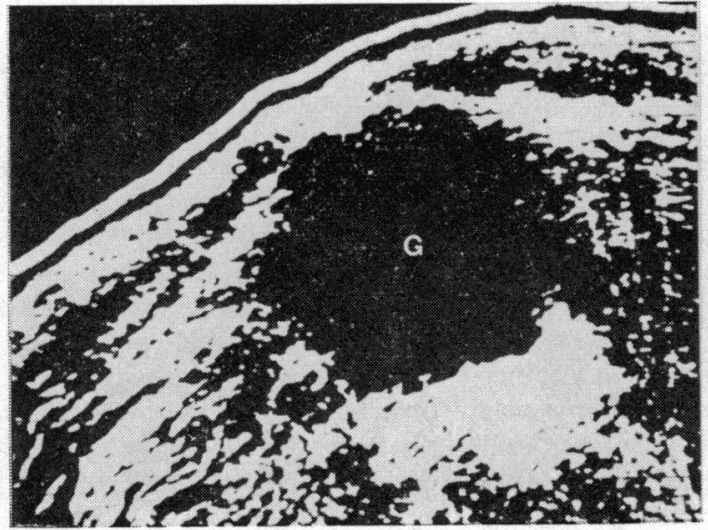

Fig. 4c

Fig. 4 Transverse ultrasonic sections of upper abdomen at intervals of $5 \mathrm{~cm}$ in case 3: (a) enlarged gallbladder and right lobe of liver; (b) and

(c) grossly enlarged gallbladder beyond the edge of the liver.

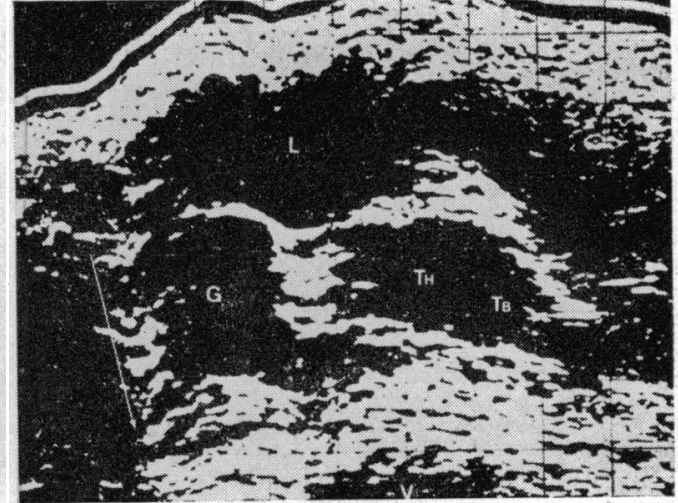

Fig. $5 \mathrm{a}$

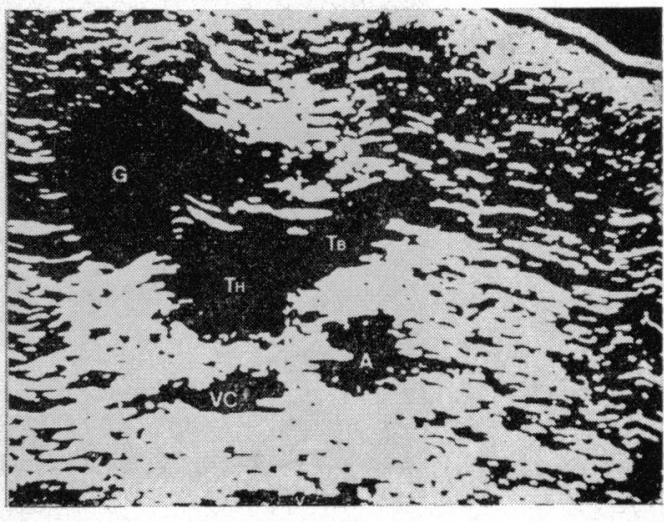

Fig. $5 b$

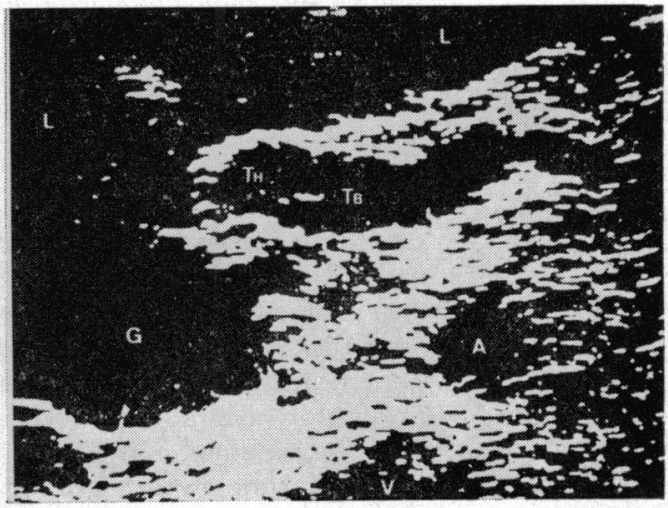

Fig. $5 \mathrm{c}$

Fig. 5a, b, and c Different examples of carcinoma of the head and body of the pancreas (cases 12, 1, 10). Arrow = streaking effect (artefact). The gallbladder is enlarged. 


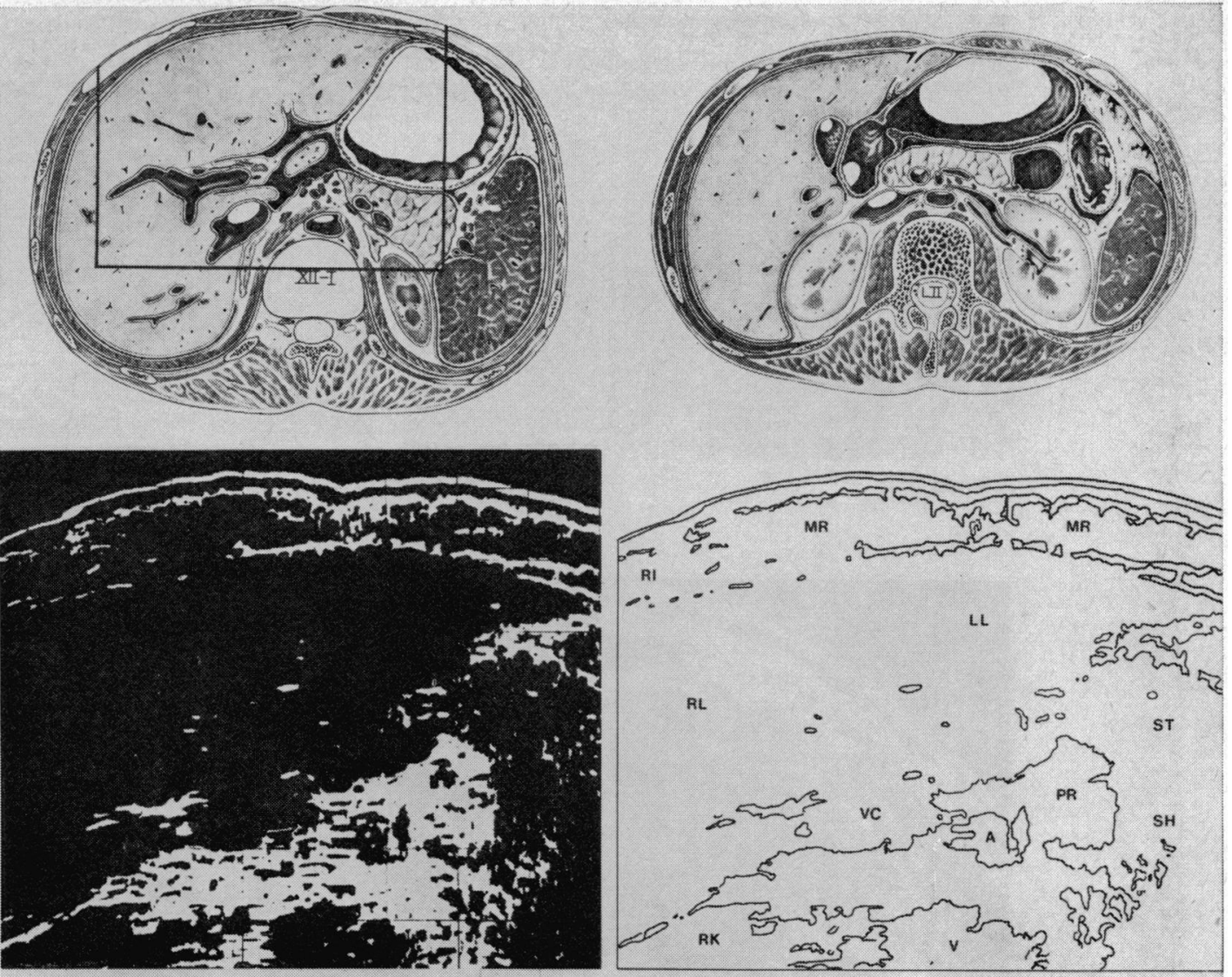

Fig. 6 Top left and right: transverse sections of the body through intervertebral disc $T h_{\mathrm{XII}}-L_{\mathrm{I}}$ and vertebra

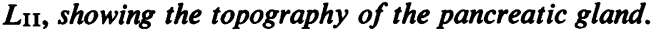
Bottom left: normal transverse ultrasonic scan corresponding to the section outlined (top left). Bottom right: line drawing of the scan (bottom left).

months after operation. One of the remaining two patients had at first a biliary drainage operation because of poor general condition and showed four weeks later, when radical surgery was planned, diffuse small liver metastases which were not present before (Fig. 1). The other patient, mentally ill, was operated on in another hospital where a choledocho-jejunostomy was done. This patient is still alive one year later, and repeated sonographic examinations show that the pancreatic tumour is increasing in size (Fig. 2). Four patients showed an inoperable tumour and only palliative surgery was done (liver metastases in three, extensive lymph node infiltration in one patient).

CASES 11 AND 12

Case 11 presented with severe itching seven months after mastectomy for cancer. The sonograms showed a tumour in the region of the head of the pancreas and a liver metastasis in the right lobe. At operation, there was a metastatic growth in the head of the pancreas and the liver metastasis was also confirmed; there was another secondary at the edge of the left liver lobe which was missed sonographically. Case 12 underwent operation for total biliary obstruction due to a tumour in the pancreas in another hospital, where a cholecysto-jejunostomy was done. Six months later the patient presented again with jaundice, ascending cholangitis, and septicaemia. The sonogram showed a grossly enlarged gallbladder and a big tumour in the region of the pancreas (Fig. 5a). The patient died in septic shock; no necropsy was performed.

\section{Discussion}

The advantages of ultrasonic scanning are that it 
is a useful screening method and gives reliable results (Blauenstein, 1969). There is no distress for the patient. The apparatus is easy to handle, transportable, and therefore useful for bedside diagnosis. The investigation can be done by one person and is not time-consuming. It can easily be repeated and used for followup studies. One ultrasonic scan is performed within five to 10 seconds and is therefore not disturbed by respiratory movements, especially in a conscious patient who can hold his breath for such a short time.

The difficulties of the method are that the position of the pancreas is most unfavourable for access by ultrasound (Holm and Mortensen, 1968). Structures which reflect or absorb ultrasonic waves lie all around the gland: the thoracic wall, stomach, liver hilus, and duodenal loop from the ventral and right lateral side, the duodeno-jejunal and colonic flexures from the left side and the vertebral column, and the muscles and retroperitoneal structures from the posterior surface of the body. In the normal case, the many vessels and ducts closely connected to the pancreas give a mosaic pattern (Fig. 6) to the echo structure which allows of no clear identification of pancreatic tissue (Holmes, 1966; Holmes and Howry, 1963). On the other hand, a tumour presents as a typical and largely echo-free zone of varying size which can easily be attributed to the pancreatic region if the surrounding anatomical structures, mainly the lower surface of the liver, aorta, and vertebral column, are clearly visible. In 50 other cases, investigated mainly for liver metastases or cirrhosis, there was never such an echo-free zone in the pancreatic region. The smallest tumour found and resected in this series measured $1.8 \mathrm{~cm}$ in diameter (Table, case 2).

The enlarged gallbladder, as it was found in all the cases of this series, gives a picture of a round, echo-free zone with sharp contours beyond the edge of the liver or of a half-moon-like structure on the lower surface of the liver (Fig. 4).

In addition, ultrasonic scanning of the upper abdomen allows an exact determination of the size of the liver and answers the question whether or not metastases are present. It is possible to localize secondaries by this technique with great accuracy and to biopsy them percutaneously (Blauenstein, Engelhart, and Müller, 1969).

\section{References}

Blauenstein, U. W. (1969). Die Ultraschallschnittbilduntersuchung am Oberbauch. Schweiz. med. Wschr.,99, 985-992.

Blauenstein, U. W., Engelhart, G., and Müller, H. R. (1969). Sonographie und stereotaktische Biopsie von Lebertumoren. Proceedings of the International Meeting on Ultrasonic Diagnostics in Medicine. Vienna (in press).

Holm, H. H., and Mortensen, T. (1968). Ultrasonic scanning in diagnosis of abdominal disease. Acta chir. scand., 134, 333-341.

Holmes, J. H. (1960). Ultrasonic diagnosis of liver disease. In Diagnostic Ultrasound: Proceedings of the 1st International Conference, edited by C. C. Grossman et al, pp. 249-263. Plenum Press, New York.

Holmes, J. H., and Howry, D. H. (1963). Ultrasonic diagnosis of abdominal disease. Amer. J. dig. Dis., 8, 12-32. 